\title{
Another cause of cardiac tamponade: ruptured coronary artery aneurysm
}

\author{
Faridah Mohd Nor*, Swarhib Shafee, Ran Zhi Tan and Lii Jye Tan
}

\begin{abstract}
Background: Coronary artery aneurysm can be defined as an abnormal dilatation of the coronaries. In recent years, the disease has been frequently encountered during surgical procedures such as percutaneous coronary intervention (PCI) and coronary computed tomography angiography (CCTA).

Case presentation: We reported a case of cardiac tamponade due to spontaneous rupture of coronary artery aneurysm in a 53-year-old Chinese man, who had collapsed and died at home after returning from work. Autopsy revealed a cardiac tamponade with ruptured aneurysm of the left circumflex artery.

Conclusion: This case highlights the need to consider ruptured coronary aneurysm as a differential diagnosis when cardiac tamponade is encountered during autopsy.
\end{abstract}

Keywords: Cardiac tamponade, Coronary artery, Aneurysm, CCTA, Forensic

\section{Background}

Coronary artery aneurysm (CAA) is defined as the diameter of the lumen of the coronary artery, generally exceeding 1.5 times the normal adjacent segment, which may involve less than one third of the whole length of the vessel (Tunick et al. 1990; Kruger et al. 1999). Another similar pathology, i.e. coronary artery ectasia (CAE), is also characterised by dilatation of the coronary artery, with a diameter exceeding 1.5 times, or more than the normal adjacent segment. However, the difference between CAA and CAE is that CAE is more diffuse, affecting more than one third of the length of the coronary artery (Aboeata et al. 2012). Based on the size of the aneurysm, it can be considered as a giant coronary aneurysm, if the diameter is more than $20 \mathrm{~mm}$ (Jha et al. 2009).

According to a survey conducted by Daoud et al. (1963), the majority of coronary aneurysm (more than $50 \%$ ) was caused by atherosclerosis, followed by congenital disorders and mycotic and syphilitic diseases (Daoud et al. 1963). The results were similar to that by Luo et al. (2016), where $68.2 \%$ of patients with CAA had coronary artery disease (CAD), in comparison to only $39.2 \%$ of CAE patients, who had CAD (Luo et al. 2016).

\footnotetext{
* Correspondence: faridah.nor@ukm.edu.my; mnfaridah@gmail.com Department of Pathology, Universiti Kebangsaan Malaysia Medical Centre, Jalan Yaacob Latif, Bandar Tun Razak, Cheras, 56000 Kuala Lumpur, Malaysia
}

Post-coronary intervention and connective tissue disorder were among the conditions reported in the incidence of coronary artery aneurysm (Swaye et al. 1983; Rognoni et al. 2007).

Patients with aneurysm of the coronary artery may be asymptomatic. However, it can cause fatal complications such as myocardial infarction and cardiac tamponade. We, thus, reported a case of sudden death due to ruptured aneurysm of coronary artery in a 53-year-old male, who had no history of connective tissue disorder prior to his death.

\section{Case presentation}

A 53-year-old Chinese man was found collapsed and died at home. He had previous history of gouty arthritis. $\mathrm{He}$ was brought to the mortuary of the Universiti Kebangsaan Malaysia Medical Center for an autopsy upon request by the police.

Autopsy showed the body of an obese male, with a height of $165 \mathrm{~cm}$ and body weight of $82 \mathrm{~kg}$ (body mass index of 30.1). External examination showed no evidence of trauma. A 'blue dome' sign of the heart indicated cardiac tamponade (Fig. 1), and about $500 \mathrm{ml}$ of blood was drained from the pericardial sac. The heart weighed $600 \mathrm{~g}$ (normal heart weight in an $80 \mathrm{~kg}$ male is 350 to 420 g) (Kitzman et al. 1988; Hangartner et al. 1985), and the coronary arteries arose normally from 


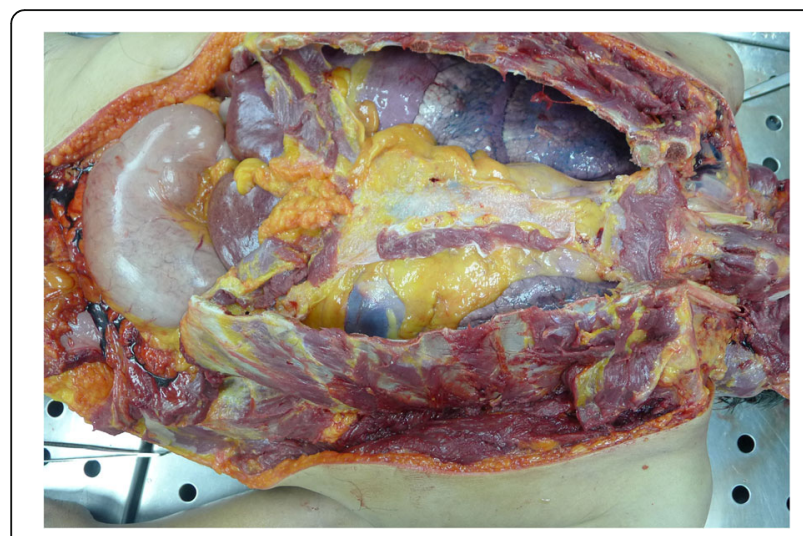

Fig. 1 Blue dome sign (arrow) in the left thoracic cavity

the aorta. There was an aneurysmal dilatation $(3 \times 7 \mathrm{~cm})$, extending from the left main coronary artery (LMCA) to the proximal part of the left circumflex artery (LCX) (Fig. 2).

The aneurysm had ruptured superiorly at the left atrium, just below the left auricle. The site of perforation $(0.5 \times 0.5 \mathrm{~cm})$ was found below the left auricle (Fig. 3). There was a haematoma $(10 \times 6 \mathrm{~cm})$ around the ruptured site (Fig. 4). The left anterior descending artery was $50 \%$ occluded by atheroma, $1 \mathrm{~cm}$ in length at about $1 \mathrm{~cm}$ away from the coronary ostium. The right coronary artery was patent. The heart valves were unremarkable. The left ventricle was concentrically thickened $(20 \mathrm{~mm})$. Further investigation revealed medial cystic degeneration of the tunica media (Fig. 5a) and haemorrhages within the tunica adventitia from histology of the aneurysm (Fig. 5b). Verhoeff-Van Gieson (EVG) elastic stain of the artery exhibited disruption of the internal elastic lamina layer (Fig. 6). Histology of the kidney showed hyaline thickening of the glomerular arteriole, which was indicative of underlying hypertension (Fig. 7).

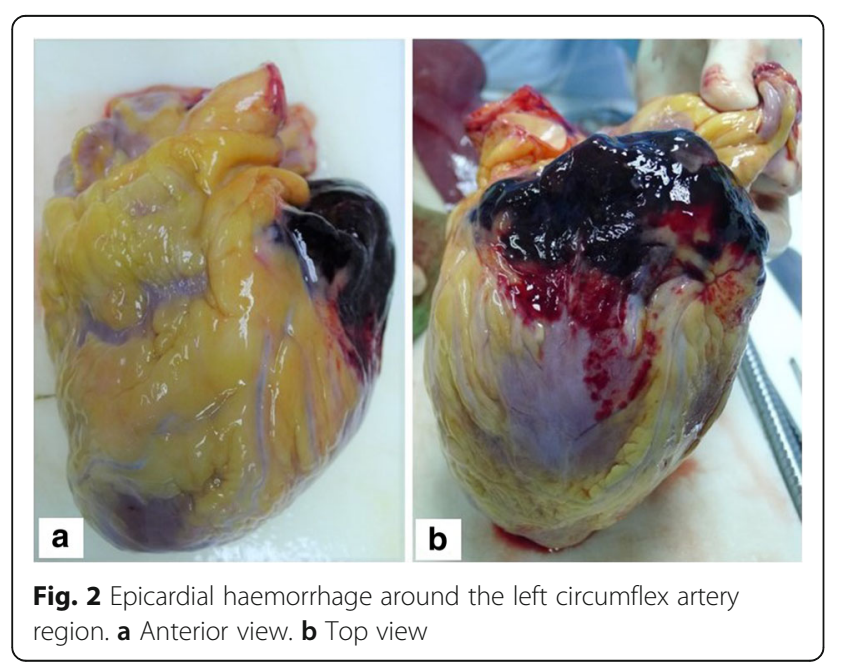

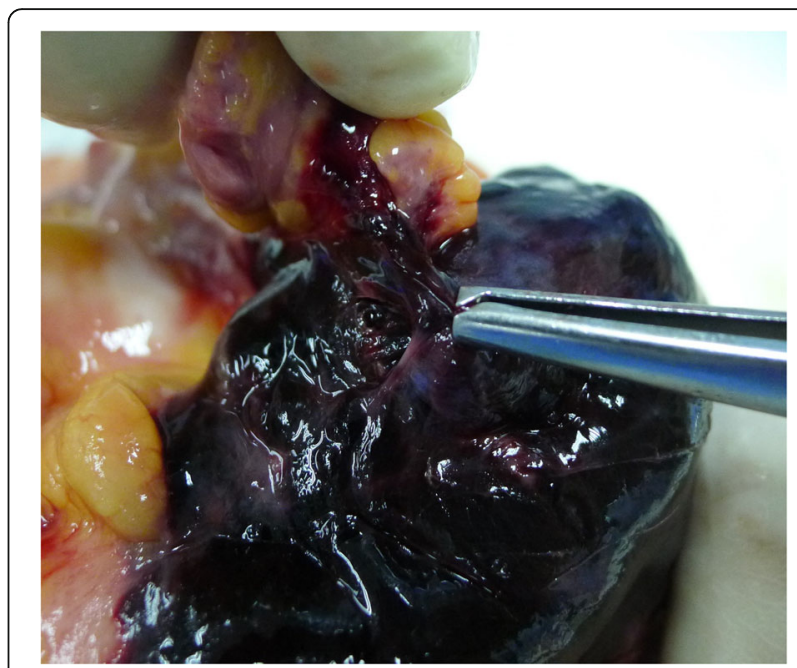

Fig. 3 Ruptured site from underneath the auricle of the left atrium

\section{Discussion}

Ruptured aneurysm is a rare complication of CAA, besides thrombosis, embolization and ischaemia (Daneshvar et al. 2012). Once CAA is ruptured, it can cause cardiac tamponade and sudden death can occur. The incidence of CAA was reported to occur between 1.5 and $4.9 \%$. The RCA is the commonest coronary artery being affected (Syed and Lesch 1997; Hartnell et al. 1985), with LMCA being the least involved in aneurysm, as none was seen in a survey by Swaye et al. (1983) $(n=1200)$, and only 22 were seen in another survey $(n=22000)$ (Topaz et al. 1991).

In this interesting case, the diameter of the dilated LCX was $3 \mathrm{~cm}$, which was 1.5 times bigger than the diameter of the normal adjacent segment $(0.5 \mathrm{~cm})$. The total length of the dilatation was $7 \mathrm{~cm}$, where $3.5 \mathrm{~cm}$ was located at LMCA, which extended to LCX for another $3.5 \mathrm{~cm}$. The dilatation at LCX had involved one third of the whole length of the artery $(10 \mathrm{~cm})$. The aneurysm had involved LMCA, which extended to the proximal part of LCX, and

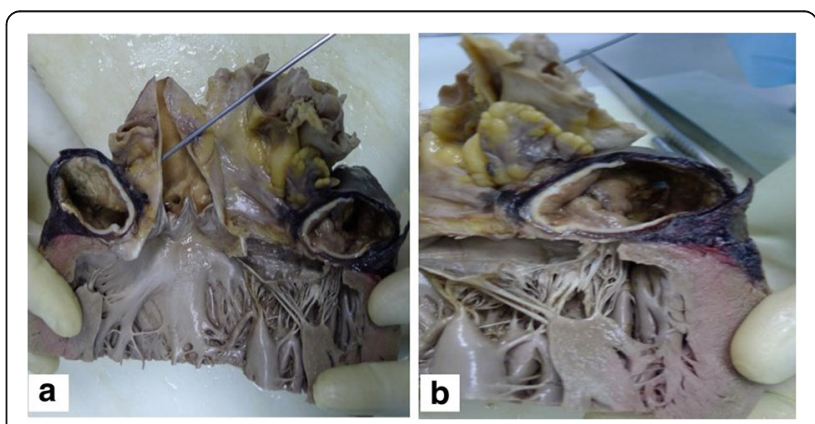

Fig. 4 Aneurysmal dilatation of the left main coronary artery, extending to proximal left circumflex coronary artery. A probe was inserted from the left coronary ostium into the left main coronary artery. a View upon opening of the aortic valve. $\mathbf{b}$ Closer view of the ruptured CAA 


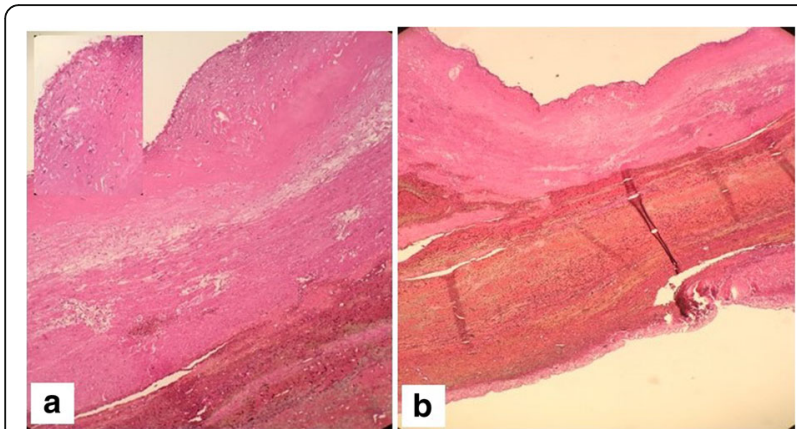

Fig. 5 a Photomicrographs of the coronary arterial wall showing medial cystic degeneration (10x magnification). No evidence of vasculitis was noted. Inset shows intima with atheromatous plaques (20x magnification). b Photomicrograph of the coronary arterial wall showing dissection of the coronary artery at the tunica adventitia (10× magnification)

these findings were rare and atypical. This giant aneurysm was almost similar to a previous case, where the aneurysm $(7 \times 5 \times 4 \mathrm{~cm})$ was presented at the right coronary artery (Kondo et al. 2015). The most likely cause of the aneurysm was coronary atherosclerosis with underlying hypertension

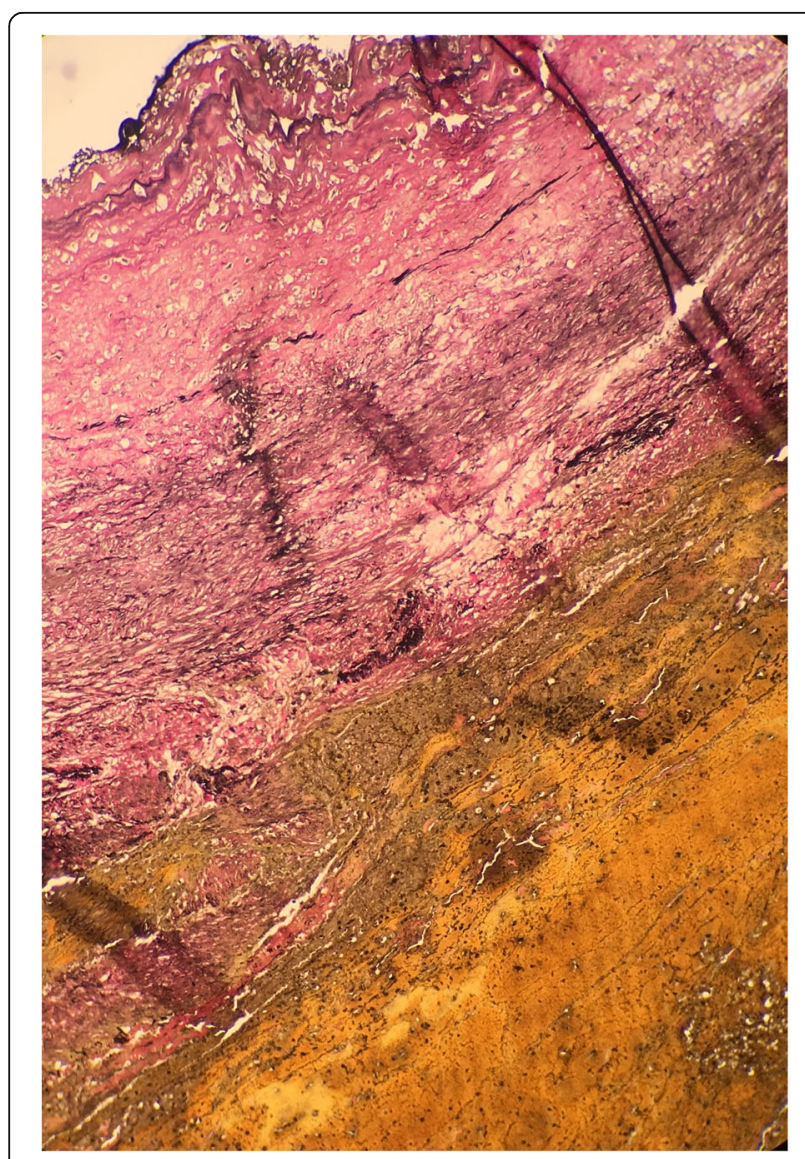

Fig. 6 Disrupted internal elastic lamina in the aneurysmal wall under EVG staining (arrow) (10× magnification)

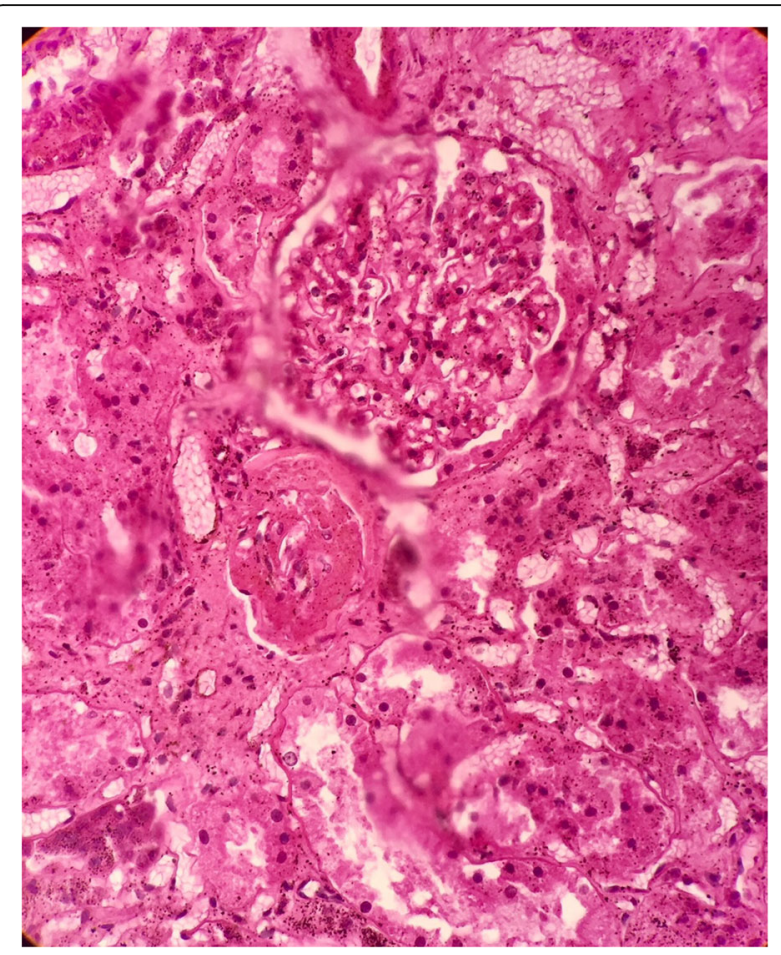

Fig. 7 Histology of kidney showing hyaline thickening of the arteriole (40× magnification)

as the predisposing factor, which led to rupture of the aneurysm.

\section{Conclusion}

In conclusion, this case represents a giant coronary artery aneurysm in an atypical location, i.e. left main coronary artery. It is worth mentioning that ruptured coronary artery aneurysm found during autopsy must always trigger a differential diagnosis that includes cardiac tamponade.

\section{Abbreviations \\ CAA: Coronary artery aneurysm; CAE: Coronary artery ectasia; CCTA: Coronary computed tomography angiogram; EVG: Verhoeff-Van Gieson elastic stain; LCX: Left circumflex coronary artery; LMS: Left main stem; LMCA: Left main coronary artery; PCl: Percutaneous coronary intervention}

\section{Acknowledgements}

We would like to thank all the forensic staffs of Universiti Kebangsaan Malaysia Medical Centre and the police officers who were involved in the investigation of this case.

\section{Authors' contributions}

All authors have made substantial contributions to this article. All authors read and approved the final manuscript.

\section{Ethics approval and consent to participate}

This is a case report, and the issues on publication have been informed to the deceased's wife. The deceased's wife had consented for the case report publication.

\section{Consent for publication}

The wife of the deceased consented for this case report publication with the condition that the deceased's details remained anonymous. 


\section{Competing interests}

The authors declare that they have no competing interests.

\section{Publisher's Note}

Springer Nature remains neutral with regard to jurisdictional claims in published maps and institutional affiliations.

Received: 14 March 2018 Accepted: 5 October 2018

\section{Published online: 12 October 2018}

\section{References}

Aboeata AS, Sontineni SP, Alla VM, Esterbrooks DJ (2012) Coronary artery ectasia: current concepts and interventions. Front Biosci (Elite Ed) 4(3):300-310

Daneshvar DA, Czak S, Patil A, Wasserman PG, Coplan NL, Garratt KN (2012) Spontaneous rupture of a left main coronary artery aneurysm. Circ Cardiovasc Interv 5(5):63-65

Daoud AS, Pankin D, Tulgan H, Florentin RA (1963) Aneurysms of the coronary artery: report of ten cases and review of literature. Am J Cardiol 11(2):228-237

Hangartner JR, Marley NJ, Whitehead A, Thomas AC, Davies MJ (1985) The assessment of cardiac hypertrophy at autopsy. Histopathology 9(12):1295-1306

Hartnell GG, Parnell BM, Pridie RB (1985) Coronary artery ectasia. Its prevalence and clinical significance in 4993 patients. Br Heart J 54(4):392-395

Jha NK, Ouda HZ, Khan JA, Eising GP, Augustin N (2009) Giant right coronary artery aneurysm. J Cardiothorac Surg 4(1):18

Kitzman DW, Scholz DG, Hagen PT, Ilstrup DM, Edwards WD (1988) Age-related changes in normal human hearts during the first 10 decades of life. Part II (maturity): a quantitative anatomic study of 765 specimens from subjects 20 to 99 years old. Mayo Clin Proc 63(2):137-146

Kondo T, Takahashi M, Nakagawa K, Kuse A, Morichika M, Sakurada M, Asano M, Ueno Y (2015) Rupture of massive coronary artery aneurysm resulting in cardiac tamponade. Leg Med (Tokyo) 17(5):388-390

Kruger D, Stierle U, Herrmann G, Simon R, Sheikhzadeh A (1999) Exercise-induced myocardial ischaemia in isolated coronary artery ectasias and aneurysm ('dilated coronopathy'). J Am Coll Cardiol 34(5):1461-1470

Luo Y, Tang J, Liu X, Qiu J, Ye Z, Lai Y, Yao Y, Li J, Wang X, Liu X (2016) Coronary artery aneurysm differs from coronary artery ectasia: angiographic characteristics and cardiovascular risk factor analysis in patients referred for coronary angiography. Angiology 68(9):823-830

Rognoni A, Ferrerob V, Teodoric G, Ribichini F (2007) Successful surgical treatment of a giant coronary aneurysm communicating with the right atrium. J Cardiovasc Med 8(12):1061-1064

Swaye PS, Fisher LD, Litwin P, Vignola PA, Judkins MP, Kemp HG, Mudd JG, Gosselin AJ (1983) Aneurysmal coronary artery disease. Circulation 67:134-138

Syed M, Lesch M (1997) Coronary artery aneurysm: a review. Prog Cardiovas Dis 40(1):77-84

Topaz O, DiSciascio G, Cowley MJ, Goudreau E, Soffer A, Nath A, Lanter P, Vetrovec GW (1991) Angiographic features of left main coronary artery aneurysms. Am J Cardiol 67(13):1139-1142

Tunick PA, Slater J, Kronzon I, Glassman E (1990) Discrete atherosclerotic coronary artery aneurysms: a study of 20 patients. J Am Coll Cardiol 15(2):279-282

\section{Submit your manuscript to a SpringerOpen ${ }^{\odot}$ journal and benefit from:}

- Convenient online submission

- Rigorous peer review

- Open access: articles freely available online

- High visibility within the field

- Retaining the copyright to your article

Submit your next manuscript at $\boldsymbol{\nabla}$ springeropen.com 